\title{
DIAN LI
}

University of Arizona and Sichuan University

SHUANG LUO

University of Arizona

\section{The selfie of the other: The Chinese dream in films and tourism}

\section{ABSTRACT}

Lost in Thailand (Xu, 2012) and Finding Mr. Right (Xue, 2013) are two recent box office hits in China. Set in locales outside China, the films are designed to ride the wave of the country's booming outbound tourism. The narrative of travel connects profoundly with the discourse of the Chinese Dream in that it reproduces the allure of economic prosperity and materialistic bliss. On the other hand, the films also bring into play the introspection that questions the very meaning of this dream, the cost of monetary excess and moral degradation in particular. In various intercultural encounters of the characters, the Chinese self is tested and constructed in familiar but reconstituted spectacles and symbols of global dimensions.

By now the 'miracle' of China's economic development has become a familiar and celebrated narrative for the Chinese people. With the rapid accumulation of wealth and material possessions during the past three decades comes a sense of supreme self-confidence widely felt in a nation that is in her strongest position ever, economically speaking, since the beginning of the modern era.

\section{KEYWORDS}

the Chinese Dream tourism self-image othering intertextuality transcultural visuality 
A most powerful and direct expression of this self-confidence was the proposal of the 'Chinese Dream' 中国梦 as the defining ideology of a national resurgence by the then newly appointed President Xi Jinping in 2012. China has since been boldly articulating its aspiration towards a path of continual economic growth and its intention of evoking the nation's historical heritage and traditional culture as a way to make visible its role in today's world (Tatlow 2014). Even though the goals of the 'Chinese Dream' are popularly described as 'a prosperous state/country, a rejuvenated nation, and a happy people' (guojia fuqiang, minzu zhengxing, renmin xingfu 国家富强，民族振兴， 人民幸福) in the official literature of propaganda, there is no mistake that the heart of the Chinese Dream is a grand vision consisting of multiple economic, political, social and cultural agendas.

This grand vision, however, is not without tension between its parts, particularly when the vision unleashes the figure of 'dream'. Since the collapse of imperial China at the beginning of the twentieth century, the narrative about the dream, or its various equivalents such as ideal (lixiang 理想), goal (mubiao 目标) and so on, was proposed at every crucial historical turn to galvanize the Chinese populace to achieve shared political and social goals. Nationalism in times of radical reform and revolution, socialism and communism during the Mao era and modernization under the leadership of Deng Xiaoping were all indispensable elements of a Chinese Dream narrative consistent with a utopian wish for the future. The current version of the Chinese Dream is no different in its futuristic aspirations, and no different in its invocation of the past for these aspirations, but this time such invocation is more vivid and forceful in the context of globalization, which China has helped to make possible and through which China is increasingly foregrounding its narrative of the nation and the self.

There is no better emblem of a globalizing China than the country's outbound tourism. On the one hand, the ever-gathering presence of Chinese students, business people and tourists in every corner of the world is a remarkable sight that has been attracting admiration and envy, scrutiny and prejudice. On the other hand, this presence represents an encounter with the 'foreign' for the Chinese people on their own terms, an encounter that subverts historical consciousness and creates spaces of new self-constructions. This is virtually a dream-come-true for millions of Chinese people for whom tourism abroad was a mere fantasy just a generation ago. What happens when a textualized notion of the foreign clashes with the experienced foreign? When a thrill-seeking adventure turns into an introspective journey, what does a tourist bring home beyond a few meretricious souvenirs? These questions lead us into two recent films 泰圆 Taijiong (Lost in Thailand) and 北京遇 上西雅图 Beijing yushang Xiyatu (Finding Mr. Right) that feature the theme of outbound tourism. Box office champions of the year 2013, these popular films create tales of foreign travels that not only capture the fancy of the foreign for a domestic-bound audience but also turns this travel into a journey of self-discovery and self-redemption. They are, this article will make clear, an aesthetic rendition of the Chinese Dream in a space of ironies and contradictions, for the dream is not presented as an informing, steadfast essence as prescribed by the policy documents of the government but a self-conscious construction contingent upon the lived and mutable experience of the dream seeker. The foreign trip in the films is not merely a thrilling adventure of exoticism but more importantly is a formative experience in which a new personalized dream emerges from the ruins of the Chinese Dream. The tour abroad 
becomes a figure of a continuous selfie-taking process as one encounters the other through the physical as well as figural space of outbound tourism.

\section{THE CHINESE DREAM IN THE SPACE OF TRAVEL}

When analysing the sustainability of China's tourism sector, David Weaver points out that tourism has the capacity to enable many objects of the Chinese Dream such as economic growth, more consumer goods, increased happiness, personal freedom, etc. (2015: 54). Among different types of tourism, outbound tourism, according to Weaver, is an exclusive aspiration for most Chinese consumers and appears to represent a higher form of the Chinese Dream (2015: 55). The reports on outbound tourism released by the China Tourism Academy in the past years confirm Weaver's view. In 2012, the number of Chinese outbound tourists reached 83 million, and Chinese travellers spent US \$102 billion abroad; and in 2013, approximately 98 million Chinese tourists went overseas and spent US $\$ 130$ billion abroad (SOHU 2013). All evidence suggests that this growth of Chinese outbound tourism will continue into the foreseeable future.

The commercial success of the films Lost in Thailand and Finding Mr. Right is a reflection of China's continuing 'tourism craze' (luyou re 旅游热), with the former taking in approximately 1.2 billion RMB (US \$200 million) and the latter 515 million RMB (US \$85 million) at the box office, which put them on the short list of China's blockbusters. Similar in many aspects to the buddy films and the road movies made in Hollywood, Lost in Thailand presents three Chinese men's tourist misadventures in Thailand. The film begins with Xu Lang touting his just completed invention of a gasoline additive called 'Supergas', which will help any automobile achieve super high mileage, and which has the potential to change the face of the Chinse auto industry forever. In order to secure the patent of the invention, however, Xu Lang must obtain the authorization from his boss and the company's principal shareholder Mr Lao Zhou, who is attending a meditation seminar in a Buddhist temple somewhere in Thailand. Despite his wife's threat of divorce, $\mathrm{Xu}$ Lang embarks on a journey to find Mr Lao Zhou. What Xu Lang does not know is that he is tailed by Gao Bo, an office rival who desires the same thing but only for himself. On the flight, $\mathrm{Xu}$ Lang meets his seatmate Wang Bao, a pancake seller from Beijing who is on a sightseeing trip to Thailand. Initially repulsed by Wang Bao's boisterous stupidity, Xu Lang nevertheless takes him in for a travelling companion, and Wang Bao proves handy to help thwart Gao Bo's annoying shadowy presence. The three of them then entangle in a series of spectacular misadventures as they trek into the heart of Thailand to an unknown destination. When they finally arrive at the jungle site of Mr Lao Zhou's meditation, Xu Lang gets the paper of authorization after a hard fight but he tears it into pieces against the wind. He has come to the realization that his pursuit is meaningless after all.

Thailand is a newly discovered hot destination for China's outbound tourists, but the United States is still the most popular choice by a good margin, where the movie Finding Mr. Right sets out to tell a story of specialized birth tourism. The female protagonist Wen Jiajia is introduced as a mistress of a rich Beijing businessman Mr Zhong. Having become pregnant with Mr Zhong's child, Jiajia is sent to Seattle to give birth to the baby for the desired effect of secrecy and the added benefit of US citizenship. The person hired to meet Jiajia at the airport is Frank, who is a new Chinese immigrant. At the illegal 'maternity house', Jiajia meets two other mothers-to-be, Zhou Yi and Chen 
Yue, who are having babies in the United States for their own reasons. The story of quarrel and camaraderie of three expectant women living in one house is a subplot to the unfolding crisis in Jiajia's life: the challenge of pregnancy, cultural shock, the shadowy life of a mistress and finally Mr Zhong's betrayal. Jiajia finds Frank to be her only companion in a foreign land. Frank's quiet warmth provides not only a source of comfort but also a prospect for self-examination. Their slow coming together finally culminates on the observation deck of the famed Empire State Building in New York.

Although the Chinese Dream is mostly promoted as a domestic agenda, tourism in Lost in Thailand and Finding Mr. Right places the Chinese Dream in the context of globalization so that China not only projects its success in economic development on the Chinese tourists but also announces the Chinese Dream to the world through these dreamers in action. When Jiajia impulsively decides to fly to New York with Frank's daughter Julie upon watching the American movie Sleepless in Seattle, the filmmaker is charting a notion of the dream in terms of consumption capacities and the freedom to travel. The impression of Chinese tourists' supreme command of economic capital is reinforced in Lost in Thailand. To the extent that today's globalized tourism sites admit tourists more likely in terms of their spending habits than in terms of their individual identity, a tourist's financial standing, rather than his or her place of origin, becomes a crucial factor in determining how well he will be received by his hosts. Therefore, when $\mathrm{Xu}$ Lang plans to stay one night in the fanciest hotel in Bangkok after losing his passport, he does not seem to worry much about the possible trouble with his identification because the premium credit card he presents at the hotel is sufficient evidence of his propriety. While travelling from Bangkok to Chiangmai with Wang Bao, Xu Lang barely encounters any inconvenience caused by the lack of a Chinese passport. Rather, he always seems to have access to efficient transportation and ever-present technological devices throughout the entire accident-prone journey. It is China's soaring economy that enables Chinese tourists to spend their way in and out of tourist sites. Tourists like Jiajia and Wang Bao are highly conscious of their newly acquired status of access, so they are 'selfie' enthusiasts, with instant updating of their self-portraits on China's blooming microblogging websites such as Weibo. These selfies of toothy grins and two-finger victory signs are not only a way of communicating promise to the dreamers of the Chinese Dream at home but also a message of confidence to the world.

The success of the American road movie as a genre, according to Steven Cohan and Ina R. Hark, depends on the availability of a cinematic space for the exploration of tensions and crises that are the product of key historical moments (Cohan and Hark 1997: 2). This cinematic space for Lost in Thailand is the rendering of tourism as a narrative of cross-cultural adventure, which functions both as an outward journey of thrill and pleasure and as an inward reflection on the experience of lack and loss. The potent sense of crisis in the film is primarily felt in the interpersonal relationships, which are put at risk due to the protagonists' excessive pursuit of career success and business profit. At the beginning of the film, as Xu Lang introduces 'Supergas' to his wife in an attempt to persuade her to hold off on the divorce proceeding, his very image of success as a scientist-businessman stands in sharp contrast with his failure as a husband and a father, because he is oblivious to the needs of others around him. Insisting upon a return of his investment on 'Supergas', Xu Lang chooses a trip to Thailand over his family, thus setting up suspense to the outcome of his adventure, which in turn suggests the insecurity-driven mechanism 
embedded in the space of China's outbound tourism. If family upheaval is the price $\mathrm{Xu}$ Lang must pay for career success, then friendship and business ethics are what Gao Bo sacrifices for his own pursuit of money and power, which is a reflection of the cutthroat competition and office politics rampant in China's business culture. Gao Bo used to be Xu Lang's best friend in college but now becomes his nemesis after he senses the vast commercial potential of the 'Supergas' invention. To keep Xu Lang in his grasp, Gao Bo applies an impressive array of cutting-edge technologies such as radio-tracking devices, a SIM card locator and a short-circuited laptop in addition to old-fashioned methods like tailing and hired assailants, which work together to turn a reasonable business dispute into a comedic satire, a plot set up that clearly references the widespread but also much maligned ethic of achieving success by all means. Ironically, Gao Bo fails exactly where he succeeds, because the Xu Lang he finally tracks down is not the person that the tracking intends to capture. Gao Bo beats his competition, but he gets nothing in return.

Cutthroat competition is a rite of passage for Chinese businessmen, which may be recognized as simply a convention when globalization homogenizes the process of economic development all over the world. Yet cultural crisis, and especially the loss of tradition after a long period of singular focus on economic growth, confronts the Chinese society with more urgent and specific questions about self-identity and cultural values. In recent times, one sees the increasing presence of tradition in all facets of Chinese society, from the insertion of classics in school textbooks and President Xi Jinping's abundant references to old sages in his public speeches to the return of private schools for boys and girls in the style of Confucian education models. Furthermore, the very formation of the Chinese Dream, as pointed out earlier, has an unmistaken echo of China's past. It seems that tradition in its various contemporary configurations has become a necessity in times of rapid and unsettling changes. In Lost in Thailand, the idea of tradition is a clear presence, but the applicability of its values is also a questionable proposition. For example, Xu Lang's manipulation of his travel companion Wang Bao suggests a total disregard of traditional ethical and moral codes, the ones embedded in Chinese classics. His concoction of their 'Thailand Legend' is not only a parody of hyperbole and self-promotion prevalent in popular culture but also a subversion of the conventions of interpersonal relationship, such as those clearly spelled out in Confucian teachings. 'Tuandui 团队' (team, group) is a modern neologism, but its concept may be traced back to the Chinese character 'ren 仁'. This character not only pictographically designates that two people come together and form a team but also figuratively means benevolence, kindness, sincerity and thoughtful consideration, all of which are core values of the Confucian notion of humanity. In this sense, a team is not merely a physical association formed by people but also should be an ethical move towards healthy interpersonal relations. However, Xu Lang's 'team-up' with Wang Bao defeats all of these purposes. He convinces Wang Bao that 'on the road, [people are] just like a team' (zuhe 组合) even though he does not believe it and did not like his seatmate that much initially; he rhetorically questions Wang Bao, 'did your mom tell you that the most people in the world are good', while he hides his motives and lies to Wang Bo all the time. The fact that Wang Bo appears sweet-natured and innocent (played by the popular actor Wang Baoqiang, who makes a career of playing lovely but easily beguiled characters) works to emphasize the points that businessmen are not trustworthy and that we have lost values and purpose due to the corrupting influence of money and greed. 
1. The increasing number of foreign nationals travelling to the United States solely to give birth has begun to catch the federal government's attention. In March 2015, federal agents raided about twenty homes and apartment complexes in Orange, Los Angeles and San Bernardino Counties.

2. The Chinese government announced the end of the one-child policy in October 2015.

3. Lost in Thailand is well liked in Thailand because the film's popularity made the number of Chinese tourists travelling to Thailand go up by 10 per cent in 2013. To recognize the film's contribution to the tourist industry, the then prime minister of Thailand Yingluck Shinawatra met the cast and gave the director Xu Zheng an award in March 2013.
While Lost in Thailand illustrates the possible cost in the pursuit of the Chinese Dream, Finding Mr. Right questions its inherent tension between the personal and the national. In recent years, the phenomenon of pregnant Chinese women coming to the United States to have their babies has been well reported. ${ }^{1}$ The three women in the film, Jiajia, Zhuo Yi and Chen Yue, are not different from the many other so-called 'maternity tourists' on the surface, but there are nuanced differences among them that may help explain the forces that drive the booming 'birth tourism' business.

When Jiajia confesses to Frank that her lack of a marital relation with Mr Zhong prevents her from obtaining legal permission to give birth to her baby at home and to register the baby legally after she is born, the film makes clear that it is Jiajia's anxiety over the 'legality' of her anticipated baby back to China, rather than the coveted US citizenship that comes with a US-born baby, that is the underlying motivation for her journey to America. For Zhou $\mathrm{Yi}$, it is being a lesbian mother who worries about the prospect of having a child out of wedlock. Chen Yue, on the other hand, wants to have a second child, another illegal wish that will have serious consequences beyond monetary punishment for a violator. ${ }^{2}$ So the Dream fulfils but it also prohibits; the prohibition happens when the wishes conflict between the individual and the collective. While the three mothers-to-be stay in the 'maternity centre' in Seattle, which is itself a stealthy operation if not outright illegal in the eyes of the local law, and wait for Frank to ferry them around, Chinese audiences watch the pampered women indulging in materialistic abundance and comforting yet conflict-laden sisterhood. Naturally they watch them with envy and admiration because only those women of good resources can afford to be maternity tourists, but they are also watching a display of insecurity and helplessness that is deeply unsettling. These feelings of insecurity and helplessness are the result of wishes clashing with wishes, desires winning over desires, all part of the discourse of the Chinese Dream. If to give birth in America is a dream for these three women and many others, a dream built on China's overall economic prosperity, national confidence and cultural renaissance, it is also an expression of aspirations that are not recognized as 'proper' dreams. When Chinese women choose to have babies on the other side of the border and thus support a thriving industry of birth tourism, does this signify the realization of the Chinese Dream or foretell the failed promises of its delivery?

\section{THE ENDEARMENT OF HETEROTOPIAS}

In recent times, a growing number of Chinese films are shot abroad. The competition between Chinese films and foreign (mostly Hollywood) films over China's domestic audience and the Chinese film industry's aspiration to reach global audiences, are the two major reasons for the attractiveness of a foreign setting both in the narrative of the filmic story itself and the aspect of filmmaking such as the use of non-Chinese actors and the quick adaptation of new Hollywood technology. On the one hand, the authorities lend a helping hand by imposing a quota on the number of foreign films shown in Chinese theatres so as to protect the Chinese film industry as a whole, and the industry then responds with a market-driven move of incorporating more elements of globalization to satisfy the Chinese audiences' craving for a taste of the foreign (Wang and Kraus 2002: 433). On the other hand, the ever-growing presence of foreign settings in Chinese films offers global allure and helps maximize box office receipts, especially in regions where they are shot. ${ }^{3}$ 
To create a foreign setting is to infuse the film with a global 'feel' and exotic flair. More importantly, the presence of the foreign in Chinese films, especially those appearing as tourist sites such as Thailand in Go Lala Go (2010), Japan in If You Are the One II (2012), America in Old Boys: The Way of the Dragon (2014), etc., suggest a psychological obsession with 'other spaces'. The charm of the 'other spaces' is delineated in Michel Foucault's discussion about 'heteroto-

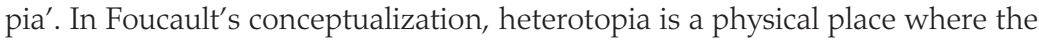
real places that exist in the very founding of society are simultaneously represented, contested and inverted, but heterotopia also emerges in the mind as a kaleidoscopic projection of incompatible places juxtaposed into an attractive whole (1986: 24-25). In Lost in Thailand and Finding Mr. Right, Thailand and America are configured as 'heterotopias' in such a way as to highlight the theme that the characters are pursuing dreams that are unlikely available to them at home. For Wang Bao whose 'bucket list' is filled with activities such as 'enjoy a Thai spa', 'fight a Thai kickboxer', etc., all things that invoke Thailand as a site of tourism, it is a wish-fulfilling space on which Wang Bao inscribes his all-consuming passion about his first trip overseas. But more importantly, when Wang Bao looks for a Thai temple to plant a cactus in order to ask for a blessing for his ill mother, and when he imagines himself going on a honeymoon trip with his idol, Chinese superstar Fan Bingbing (a real Chinese movie actress who has a cameo appearance as herself), Thailand represents for Wang Bao, the common man from China, the most optimistic and wishful expectations towards life. Similarly, as Jiajia indulges herself in the romantic ideal of Sleepless in Seattle (she tells Julie that her dream is to meet her 'Mr. Right' at the top of the Empire State Building one day), America is not only a place of escape from her scandal at home but also the setting for a genuine love story, which is lacking in her relationship with Mr Zhong.

When outbound tourism sends Chinese people to places all over the globe, China connects at the level of experience with the idea of globalization, which, as one scholar describes it, is a heterogeneous time-space where 'peoples, cultures, and commodities rapidly crisscross diverse sites and temporalities, blurring boundaries and identities, and generating tense competition and productive collaboration' (Lam 2008: 70). If the goal of nationalist resurgence in the past, as some critics argue, was mostly a response to China's strategic recollection of the humiliating experiences at the hand of the West, then today in announcing the Chinese Dream in a globalized context, China is planning for a shift of powers in anticipation of a reconfiguration of its relations with the West beyond the familiar narrative of domination and subordination (Wang 2013: 3). This aspiration of the Dream calls for a great deal of effort, which not only helps China's nation-building project at political and economic levels but also facilitates the construction of a more confident and more assured Chinese self. While China's current status as the world's second largest economy, the result of a 30-year political-economic effort, has enhanced the country's standing immensely, the image-making project (the Chinese Dream within and 'soft power' without) has just began, for the overwhelming negative perception of China in the world, facilitated by the West, is not so easy to overcome.

Here come the Chinese tourists, who ride on the wings of China's economy and spend for their self-confidence and for the goodwill of others. Finding Mr. Right has a series of shots portraying Jiajia throwing money at luxury goods with abandon while Frank drives her around and interprets her purchase commands. Frank came from China, but he is a different kind of 
Chinese now; he is doing the job just to get by, not necessarily interested in the clients he serves. The film's juxtaposition of two different attitudes towards money and consumption between a Chinese tourist and a Chinese immigrant in capitalistic America is more than for a comedic relief; it means to show that the idea of China has overtaken the idea of people when it comes to materialism and consumerism. Ostensibly, that idea of China invokes notions of development and progress, somewhat a subversion of the notion of the West itself, particularly the conventional western historicism which defines a linear temporality with Euro-America standing as the epitome of progress while non-European societies are characterized by their lack (Dirlik 1996: 97). In one scene, when we see Frank explains to Jiajia that he is to give custody of his daughter Julie to his ex-wife in order for her to grow up in a better material condition, we realize that Frank's appearance of austerity finally yields to worldly concerns. This is not a yielding to the traditional argument that mother provides better love and care for a child than father, which still echoes loudly in Chinese society in cases of divorce, but rather a yielding to the notion of family defined in terms of money and resources. That as a newly arrived immigrant Frank has neither is not surprising, but that his experience unfolds while standing alongside Jiajia's abundance is indeed notable, even somewhat amusing to the Chinese audiences familiar to the genre of 'immigrant story' ('yimin gushi 移民故事') popularized by works such as 北京人在纽约 Beijing ren zai Niuyue (Beijinger in New York) and 曼哈顿的 中国女人 Manhadun de Zhongguo nuren (The Chinese Woman at Manhattan). So in things that matter to the heart, Frank wants the best for Julie in the shadow of Jiajia; Julie is now at a stage of 'not yet', while Jiajia fully embodies its presence. Again we see a reversal of the temporal scale that western historicism has created (Chakrabarty 2000: 8). On this new temporal scale, the West is perceived as located somewhere that a fast developing China had already left behind.

In Finding Mr. Right, we also see how China's aspiration to reconfigure the historical power relation between itself and the West is framed in a gendered perspective. As has been pointed out by some critics, China's weakness and backwardness at the turn of the twentieth century has been metaphorically likened to the oppressive condition of women, and the Chinese nation, when confronted by the 'masculine' West, which was stronger and more powerful, has been reduced to a feminine other (Chong 2013: 244). Today, the same gendered language has crept into China's national narrative of strength and confidence. On the surface Frank comes to the United States for personal reasons, but every story of immigration is overlapped with a national narrative. As we get to know him at the beginning of the film, we are repeatedly given the comparative context between Frank's former self as a well-known surgeon in Beijing and his current status of a driver for hire, as if his struggle has something to do with his 'abandonment' of China. When Jiajia tries to stop him from attending his ex-wife's wedding to a white man, the language she uses is spiced with references to his manhood or lack thereof. The implication is that China itself is a resource of masculinity no longer available to Frank.

Zhou Yi's story is another engendered text, or more specifically a play on the dichotomy of femininity and masculinity that has been a common allusion to the history of domination and subordination between China and the West. Zhou Yi is a very different kind of 'maternal tourist' who wants to produce a 'Chinese heir' on American soil by means of sperm donation. As a lesbian, Zhou Yi, perhaps, is herself a Chinese woman 'corrupted' by 
the West, yet this Chinese woman is not just interested in the technology of the West but she would like to 'consume' a western man's sperm for her own good. Reproduction by sperm donation may not be as rare as before, but its implications for the future of family structure are yet to be fully understood in China, and Zhou Yi's status of both a 'maternal tourist' and a lesbian mother-to-be clearly magnifies the symbolic power of such a practice. When a Chinese woman purchases a western man's sperm in order to construct her Chinese self, especially her maternal self, she rewrites the social contract of fertility and takes control of the birth process by reducing male participation to a mere anonymity. There is no doubt that Zhou Yi's project challenges male symbolic power earnestly, but it is questionable if it weighs against the Chinese man and the western man equally. The sperm donor is later revealed to be a graduate student from Harvard University. We do not care to know who he is but we assume he is a man of superior intelligence and perhaps charming personality. It seems that the idea of the western man survives in the traces of his disappearance, and his survival is still necessary for the redemption of a Chinese woman's self-worth and the realization of her Chinese Dream.

As we examine the tortured journey of self-discovery and self-construction in the space of heterotopias in Finding Mr. Right, we cannot ignore the film's tacit acknowledgement of the existence of a power hierarchy between China and the West. No self is complete without a reference to the other, an insight eloquently presented by Edward Said in his groundbreaking work Orientalism (1995: 332). If in Finding Mr. Right, the practice of othering is to counter the hegemony of the West to make room for the emergence of a new Chinese self, then in Lost in Thailand, it actually hints at the possibility of a new power structure between China and the rest of the world. It is worth noting that the competition between $\mathrm{Xu}$ Lang and Gao Bo involves questionable business ethics that have been under much scrutiny by the world media and that the conflict plays out in Thailand is a recognition of the global reach of China's businessmen. In their battle of smarts and high-tech gadgets, Xu Lang and Gao Bo conduct themselves with superb confidence in a place they do not know. The Thai locals, who are always present yet away from the focus during their chases, seem to appear, alternately, indifferent to or in awe of their stunts. In one scene, we see Gao Bo throw a bundle of money bills to Wang Bao with the purpose of buying information from him, while a Thai shop owner looks on with perhaps admiration or wonder. This minor character does not need to be there when the exchange between Gao Bo and Wang Bao occurs, but he must be there to witness the display of a Chinese tourist's opulence. His indigenous dress and dark skin stand in sharp contrast to the well-dressed Chinese tourists, a visual construction that reminds us of the so-called privileged 'white Asians' and the poorer 'black Asians' (Lo 2010: 75), which is a replication of the familiar construct of the Western self and the Oriental other.

However, if otherness is necessary for the need of the self, it does not mean that the boundary between the two is always clear-cut and immutable. To examine Chinese tourists' global encounters with the foreign other at sites of tourism, Mary Louis Pratt comes up with the concept of 'contact zone' to not only help re-contextualize the question of the self and the other but also to encourage more critical reflection upon the binary relations such as the subject and the object, the dominated and the subordinated. Originally designated as 'the space of colonial encounters', the 'contact zone' refers to 'the space in which peoples geographically and historically separated come into contact with each other and establish ongoing relations, usually involving 
conditions of coercion, racial inequality, and intractable conflict' in general (Pratt 1992: 6). More importantly, what makes Pratt's conceptualization of the power relation distinctive from that of other scholars is her awareness of the agency of the subordinated and colonized other: when 'subordinated or marginal groups select and invent from materials transmitted to them by a dominant or metropolitan culture', even though 'they cannot readily control what emanates from the dominant culture, they do determine to various extents what they absorb into their own, and what they use it for' (1992).

Although from the perspective of the three Chinese tourists, Thailand is a site fraught with clichés and stereotypes such as ladyboys, sinister gangsters, drug dealers, white men and Thai hookers, the film does aspire to show some degree of sensitivity towards the agency of the Thai people. The Chinese tourists conceive of Thailand as many things: a place of exotic attractions, of business profits, of Buddhist training and of chaos which calls upon them to make an order. In the latter sense the three protagonists in Lost in Thailand are quite similar to the aggressive colonizers and expansionists in the colonial writing of Euro-American literature, for the 'enthnicized' Thai others in this 'contact zone' not only selectively accept but also turn what the metropolitan culture imposes on them to their advantage to some extent. In one scene, $\mathrm{Xu}$ Lang is stuck in the bad Bangkok traffic while riding a cab to catch the flight to Chiangmai. As a Beijing urbanite, Xu Lang displays total confidence in his own metropolitan experience of coping with the situation and impatiently barks at the cab driver. The cab driver, apparently a local in Bangkok, exerts the privilege of his indigenousness while remaining calm and carefree. In response to Xu Lang's rudeness, who incidentally mispronounces the horn as 'loudspeaker' in English, the Thai cabbie effortlessly speaks Thai, English, Japanese and even Chinese in succession. More interestingly, when Xu Lang comments that Thai people are always lazy, the cabbie quickly counters by saying that 'Chinese are always in a hurry'. As the cabbie, who seems to have a good knowledge about China, points out that the traffic in Beijing is even worse [than in Thailand]', Xu Lang gives out a look of utter helplessness. Chinese tourists' perception of both themselves and the Thai people is challenged when the 'Thai other' enters the conversation and brings along an alternative vision. It is now the anxious Chinese tourist, not the taxi driver, who has been 'ethnicized' in a twisted operation of ethnic stigmatization and reductionism.

While the encounter between Xu Lang and the Thai taxi driver shows that the presence of the other in Xu Lang's sense of the self, a presence of misconception and misinformation, that is to say, the chance meeting between $\mathrm{Xu}$ Lang and Wang Bao serves to further emphasize that 'otherness' is simply a part of the self-construction. In their 'Thailand Legend Combo' Xu Lang is the 'enlightened one', always imparting knowledge and wisdom about Thailand to Wang Bao. When they see a beautiful woman in their hotel's dining room, Xu Lang makes some smug comments about 'ladyboy' to an enthralled Wang Bao. They run into her again in the elevator, where $\mathrm{Xu}$ Lang continues to dispense his erudition about beauty and Thailand, asserting that 'every beautiful woman in Thailand is a ladyboy' right in front of the 'ladyboy' who presumably would not understand Mandarin Chinese. The elevator stops and out goes the 'ladyboy', along with her loud utterance of profanity in a perfect Beijing accent, which stops the two men in their tracks. To these two Chinese tourists who have absolute confidence in their knowledge, or the so-called 'objectivity', about other cultures, Thailand is situated in a timeless present and thus can be described, interpreted and theorized at will. Xu Lang's speech 
about beauty and the ladyboy is also a pronounced aesthetic judgment about Thai women, for if only ladyboys are beautiful, then Thai women must be fairly unattractive. Yet what is particularly intriguing is that the film neither presents a dramatic confrontation between Chinese tourists and Thai ladyboys, nor does it bother with an opportunity for a Thai woman to speak for herself; rather it strategically deploys a charming Chinese woman to discredit Chinese tourists' sweeping generalizations and to challenge their economy-/ culture-based superiority from 'inside'. ${ }^{4}$ When Xu Lang and Wang Bao fix the Thai other with a static, eternally frozen gaze, the other only brings their own visibility to themselves. As the Chinese woman berates the "two idiots in the elevator' while deftly revealing her identity, the self-images of Xu Lang and Wang Bao - who they are to the Chinese woman and the listener on her cellphone, and by extension, the Chinese audience - that are reflected in the eyes of the other cannot be clearer. If one's identity needs to be confirmed by the experience of identifying with the other, then the Chinese self, a subjective agent that is deconstructed by the other, as the film shows, is apparently wrought with various misunderstandings, uncertainties and doubts. The moment is a turning point in the journey of self-recovery at which the Chinese self needs to be re-oriented. Yet, will the re-orientation divert the self from the Chinese Dream or get him closer to it?

\section{THE CHINESE DREAM: THE REALIZATION AT ITS RUPTURE}

The preceding question brings us back to the meaning of the Chinese Dream, a vision which is constituted by not only material comfort but also psychological satisfaction, not only the economic benefit but also spiritual sensitivity, and not only persistently striving on the social ladder but also at improving in interpersonal relationships. To pursue the Chinese Dream, in this sense, is to attempt different paths and open up new possibilities, which is precisely the inspiration that motivates the Chinese tourists in Lost in Thailand and Finding Mr. Right. This inspiration leads those wandering characters towards a path of enlightenment and salvation, and eventually guides them to realize their dreams in some surprising ways.

As Lost in Thailand is drawing to a close, Xu Lang and Wang Bao finally locate the temple where Mr. Zhou has his retreat, but they face the biggest challenge yet to get there. First, the SUV for the 'Thailand Legend Combo' falls into a mountain stream, caused by another one of Wang Bao's 'innocent mistakes'. Wet all over like a drowned rat, $\mathrm{Xu}$ Lang appears extremely frustrated at Wang Bao. He shouts, '[i]s this Journey to the West... Getting the letter of attorney is harder than getting sutra!'. The reference to Journey to the West (Wu 1977), a classic Chinese novel, is an interesting one. In this famous story of adventure and pursuit, the pious monk Tang Seng and his three disciples overcome numerous magical monsters and evil spirits to reach India (the West) for the purpose of bringing sutras to China. In moments of temptation and despair, they always rely on the power of their faith in the Buddha. Perhaps the audience has long recognized the overwrought intertextuality between Lost in Thailand and Journey to the West, because the hints are everywhere: Wang Bao's mother's prayer, Thailand as a Buddhist country, and the mystique of Mr Zhou and his whereabouts. What this intertextuality evokes, first of all, is the motif of purpose and translation inherent in a journey narrative, but it seems that $\mathrm{Xu}$ Lang has been totally oblivious to the symbolism of the journey of which he is a central part. Now an angry
4. In the elevator scene, the Chinese woman or 'ladyboy' is actually played by a transsexual Thai actress called Rose, who is also one of the top ten transsexual queens in Thailand. This information was available to the Chinese audience because it was one of the highlights in the film's promotional materials. 
outburst changes all that. It happens in the heart of a jungle where Thailand has become an abstraction of nature itself, and where desires and frustration are dispersed along the blurred lines of time and space. It is the moment that $\mathrm{Xu}$ Lang becomes aware of himself, his status as a pilgrim in search of 'sutra', which resides in the legal document with Mr Zhou's signature. When the two travelling buddies get out of the jungle and hit the road again, they are still arguing about which way to go, but the tenor of the argument has changed. The journey must continue because Mr Zhou and his temple need to be found, where lies Xu Lang's dream for 'Supergas'. However, it is no longer a dream of having 'Supergas' but one with no reference to it.

It is easy to see how 'Supergas' is a signifier of the Chinese Dream, but harder to envision a dream without it. The attraction of Lost in Thailand is precisely its effort towards such an envisioning. That dream-fulfilling is configured as 'letting go', rather than simply 'must have' offers something refreshing, even subversive, in an age of abundance and excess. The losses in Thailand, the film seems to suggest, are the gains in China for the characters. At the end of the film, everybody recovers somewhat from their painful journeys: at the Chinese Embassy in Bangkok, Xu Lang is reunited with his wife who has retrieved his passport returned by the Thai taxi driver. Later we see Xu Lang at his daughter's birthday party, where the feeling of family joy is in the air. Gao Bo, still dripping from the Thai water splashing festival, calls his wife in great excitement while she is giving birth to a baby in France. Wang Bao is busy selling his 'homemade' pancakes, living large in the popular Chinese middle class dream. In the end, the dreams of these characters are not just a correction but also a convergence to the Chinese Dream as well.

Whereas Lost in Thailand presents its 'dream-fulfilling' happy ending in the domestic context, Finding Mr. Right transports the Chinese Dream into a transnational context. While the American setting is a clear reminder of prohibitive domestic forces - political as well as cultural - which sort out the right dreams from the wrong ones, the film presents a similarly fashioned happy ending that stresses family harmony and romantic love. After returning to China and marrying Mr Zhong, Jiajia is shown to live a luxurious but inert life. In a scene, Jiajia drives by the building of the hospital building where Frank used to work. The camera zooms in on a pensive Jiajia, then away to congested traffic, and the murky sky in thick smog. Nobody could have missed the hint of comparison here: Seattle's clear blue sky versus Beijing's gloomy cityscape, Jiajia's empty feelings now versus her charged emotions then, and mostly importantly, Frank's absence and presence. It is interesting to note that Mr Zhong has not yet shown his face: we hear his voice and feel his presence through Jiajia's reactions to his manipulations, but we don't know who he is. The suggestion is that he is nobody and everybody, the personification of easy money and materialistic excess that attempt to pervert the Chinese Dream at every turn. Jiajia has not succumbed to his seduction for a while, but the travel to Seattle presents an opportunity for an escape. She cannot stay away from him in China because he is everywhere; she must go back to America to make the escape successful.

The final scene of Finding Mr. Right is Jiajia meeting Frank at the observation deck of the Empire State Building. Many a Chinese critic has pointed out the scene's connection with the ending of the film Sleepless in Seattle. Some praise it as the Chinese filmmaker's 'salute' to the Hollywood classics while others dismiss it as a cheap imitation with no inspiration (Liang 2013). The final scene is just one of the many places that the film pays tribute to Tom Hank's and Meg Ryan's riveting tale of romance, but Sleepless in Seattle itself 
is referring to an early Hollywood film An Affair to Remember (McCarey, 1957), which is a remake of the film Love Affair (McCarey, 1939). In all these films, the Empire State Building figures as a site for the realization of enduring love. By throwing itself into this timeless flow of romantic ideals, Finding Mr. Right constructs a version of the Chinese love story that highlights both its transnationality and intertextuality; it is the future of the past that holds the promise of escaping the present muddled in self-delusion and excess. It is at this future of the past that the narratives of the Chinese Dream and globalization converge in a spectacular fashion. As the camera moves from a close-up of Jiajia and Frank in a blissful embrace and then zooms out to a wide shot of the whole skyline of New York City, the film seems to transpose the view of the two protagonists with that of the audience about the iconic place. The couple is shown to be contained by the landscape of America, neither assimilated into it nor standing out of it, playing out a love story in a timeless space and living a dream that radiates unlimited allure for the audience at home.

The allure of a dream is its network of possibilities and the power to describe what is yet to come. The Chinese Dream has been an appealing catchphrase that envisions an economically strong, politically benevolent and culturally vibrant nation in which people live happily with the benefits of modernization. However, as the analysis of the films suggest, the Chinese Dream in operation is also a complicated, dualistic and even paradoxical representation of the Chinese experience in the real world: it fires up people's expectations and optimism but also rekindles the feelings of uncertainty and anxiety deeply seated in the Chinese psyche; it facilitates the construction of the Chinese self in an expanded context but also enables the subversion of superiority and conceit in the global encounter; it sells the notion of prosperity while engaging in an introspective examination of the meaning of contemporary life itself. The Chinese Dream, as it turns out, delivers only when it questions itself and guides people away from where they are in the habit of going.

\section{REFERENCES}

Chakrabarty, Dipesh (2000), Provincializing Europe: Postcolonial Thought and Historical Difference, Princeton: Princeton University Press.

Chong, Gladys Pak Lei (2013), 'Chinese bodies that matter: The search for masculinity and femininity', The International Journal of the History of Sport, 30: 3, pp. 242-66.

Cohan, Steven and Hark, Ina R. (1997), The Road Movie Book, London: Routledge.

Dirlik, Arif (1996), 'Chinese history and the question of orientalism', History and Theory, 35: 4, pp. 96-118.

Farrugia, Christine A. (2014), Charting New Pathways to Higher Education: International Secondary Students in the United States, Institute of International Education, http://www.iie.org/Research-and-Publications/ Publications-and-Reports/IIE-Bookstore/Charting-New-Pathways-ToHigher-Education-International-Secondary-Students-In-The-UnitedStates. Accessed 21 April 2015.

Foucault, Michel (1986), 'Of other spaces: Utopias and heterotopias', Diacritics, 16: 1, pp. 22-27.

Kang, Xiaoguang (2014), '大转轨: 全球化时代的国家 转轨理论及中华民族复 兴战略' 'Da Zhuan Gui: Quanqiuhua shidai de guojia zhuangui lilun ji zhonghuaminzu fuxing zhanlue' ('The great alignment: The theory about 
national alignment and the strategy for national rejuvenation in the era of globalization'), Chinareform, 29 April, http://www.chinareform.org.cn/ open/Theory/201404/t20140430_196022.htm. Accessed 21 April 2015.

Lam, Joseph (2008), 'Music, globalization, and the Chinese self', Macalester International, 21, http://digitalcommons.macalester.edu/cgi/viewcontent. cgi? article=1464\&context=macintl. Accessed 27 August 2015.

Liang, Zuoyue (2013), 'Beijing yushang Siyatu: Jinqian guan beilun yu fuhaohua chengshi' ('Finding Mr. Right: A paradoxical view on money and the city as a sign'), http://movie.mtime.com/163126/reviews/7582347.html. Accessed 21 December 2015.

Lo, Kwai-Cheung (2010), 'When China encounters Asia again: Rethinking ethnic excess in some recent film from the PRC', China Review, 10: 2, pp. 63-88.

McCarey, Leo (1939), Love Affair, New York: RKO Radio Picture.

McCarey, Leo (1957), An Affair to Remember, New York: Jerry Wald Productions, Inc.

Pratt, Mary L. (1992), Imperial Eyes: Travel Writing and Transculturation, London: Routledge.

Said, Edward W. (1995), Orientalism, Noida: Penguin Books.

SOHU (2013), 'Notes on the annual report of China outbound tourism development 2013-2014', http://travel.sohu.com/20140610/n400660767.shtml. Accessed 21 April $20 \overline{15 .}$

Tatlow, Didi Kirsten (2014), 'Xi Jinping on exceptionalism with Chinese characteristics', New York Times, 14 October, https://sinosphere. blogs.nytimes.com/2014/10/14/xi-jinping-on-exceptionalism-withchinese-characteristics/?_r=0. Accessed 4 May 2017.

Wan, Jihong and Kraus, Richard (2002), 'Hollywood and China as adversaries and allies', Pacific Affairs, 75: 3, pp. 419-34.

Wang, Zheng (2013), 'The Chinese dream: Concept and context', Journal of Chinese Political Science, 13: 1, pp. 1-13.

Weaver, David (2015), 'Tourism and the Chinese dream: Framework for engagement', Annals of Tourism Research, 51: 1, pp. 54-56.

Wu, Cheng'en. (1977), Journey to the West, Taibei: Shi jie shu ju.

Xu, Zheng (2012), Lost in Thailand, Beijing: Beijing Enlight Pictures.

Xue, Xiaolu (2013), Finding Mrs. Right, Beijing: BDI Films.

\section{SUGGESTED CITATION}

Li, D. and Luo, S. (2017), 'The selfie of the other: The Chinese dream in films and tourism', Asian Cinema, 28:1, pp. 39-53, doi: 10.1386/ac.28.1.39_1

\section{CONTRIBUTOR DETAILS}

Dian Li completed his Ph. D in Asian languages and cultures at the University of Michigan, Ann Arbor. He taught at Iowa State University, Ames, for two years before joining the faculty at the Department of East Asian Studies, the University of Arizona, Tucson, where currently he is an associate professor of modern Chinese literature. He is also a visiting professor at Sichuan University, China. Dian Li's primary interests of research are critical theories, Chinese films and poetry, translation studies, comparative literature and world literature. He is the author of two monographs, two book-length translations (co-translator), and over fifty essays and reviews in English and Chinese language journals. 
Shuang Luo is a Ph.D. candidate majoring in modern Chinese literature with minors in learning, reading and culture and pre-modern Chinese literature. She received her M.A. in comparative and world literature from Central China Normal University and another M.A. in English literature from Jackson State University. Her research interests include Chinese intellectuals in modern literature, transnational Chinese cinema, Chinese legends in U.S. children's literature, and British writers in the 20th century.

E-mail: luoshuang2008@gmail.com

Dian Li and Shuang Luo have asserted their right under the Copyright, Designs and Patents Act, 1988, to be identified as the authors of this work in the format that was submitted to Intellect Ltd. 